\title{
Internet and COVID-19: information and misinformation
}

\author{
Edson da Silva ${ }^{1}$ \\ Marilela Marques Toledo ${ }^{1}$
}

More than a century ago, about 50 million people died from the 1918 flu pandemic, which affected a third of the global population. At that time, challenges limited medical practice and public health interventions, and information sharing only took place by telephone, mail or direct person-to-person communication. Currently, the world is experiencing a new pandemic, COVID-19, which is affecting human health and threatening millions of lives. At the same time, the internet has become an important global source of health information [1], and communication is conducted over giant digital social media platforms capable of sharing information with great transmission speed, reach and penetration, and thus reaching billions of people to help fight the spread of the new coronavirus $[1,2]$. However, misuse of the internet poses a risk to public health, so governments should develop strategies to regulate health information on the internet, but without censoring the population [3].

The internet exerts a powerful influence on news. It is used to transfer government power to society, which today is a society that is pressing governments to make decisions, sometimes based on false news, or "Fake News." In this sense, the biggest problem with health information on the internet is that valid and reliable sources are hard to find.
Due to the importance of the internet for communication and health research, several systems and tools for evaluating the information available online have been developed. Indicators applied to a website can provide an index of the quality of its informational content. For example, the most widely used scoring systems are the Health on the Net Foundation Code of Conduct (HONcode), the Journal of the American Medical Association (JAMA) benchmarks and the DISCERN instrument.

From this perspective, a recent study evaluated the quality and readability of online information about COVID-19 on the top 110 sites selected by Google Trends in English and Spanish; it revealed that only $1.8 \%$ of them have the HONcode seal. According to the JAMA benchmark, $39.1 \%$ of these sites do not meet any of the criteria required by this tool, and only $10.0 \%$ of the sites meet the four quality criteria required by JAMA. And based on the DISCERN scores, $70.0 \%$ of the sites were classified with a low score, and none had a high score [1].

During the Munich Security Conference, held on February 15, 2020, the director general of the World Health Organization (WHO), Tedros Adhanom Ghebreyesus, stated that "we are not just fighting an epidemic; we are fighting an infodemic" —an information epidemic [4].

\footnotetext{
${ }^{1}$ Diabetes Study Group, Department of Basic Sciences of Health, Federal University of Jequitinhonha and Mucuri Valleys (UFVJM), Campus JK, 39100000, Diamantina, Minas Gerais, Brazil. E-mail: edosn.silva@ufvjm.edu.br
} 
In fact, we live in a world with too much information and misinformation in digital media, especially on social networks $[4,5]$. For these reasons, immediately after COVID-19 was declared a Public Health Emergency of International Interest, the WHO risk communication team launched a new information platform called the WHO Information Network for Epidemics (EPI-WIN), with the aim of combatting the misinformation surrounding the current pandemic [5].

In addition, the WHO has established collaboration agreements with the United Nations Children's Fund (UNICEF) and other international agencies that have extensive experience in risk communications, such as the International Federation of Red Cross and Red Crescent Societies (ICRC) [5]. Other WHO initiatives include partnerships with research and media companies such as Facebook, Google, Pinterest, Tencent, Twitter, TikTok and YouTube, among others, to combat the spread of rumors and misinformation about COVID-19. It is worth noting that the WHO recommends that all governments, companies and news organizations work together in the task of bringing information about the pandemic, but without causing hysteria. The recommendation is that this work is not only for ministers of health, but for the whole government, with an approach guided by scientific evidence and public health priorities $[5,6]$.

Science seeks to identify the relationship between interactions on social media and the type of information shared. The findings indicate that messages focused on false health information are mostly aggressive, while those based on evidence of social impact are conveyed in a respectful and transformative way. In addition, deliberative contexts promoted on social media outweigh false health information. Such evidence contributes to the advancement of knowledge in overcoming false healthrelated news shared on social media [7]. Indeed, social media is not only being used to spread false news and hate messages, but also to share truthful and supportive data with all those affected by both COVID-19 and hate messages [8]

In this context, many possibilities have been experienced with the use of social media as a tool for the management of the current COVID-19 pandemic. We highlight the use of social media for the purposes of (1) directing people to reliable sources of information on the most varied aspects of COVID-19; (2) developing measures to mitigate misinformation and the spread of false news ("Fake News"), which have caused panic in the population; (3) providing support to health services for remote assistance with providing diagnoses and measures; (4) mediating advances in remote learning and accelerating the development of research in the field of social media; and (5) promoting a culture of preparation to face COVID-19, as well as future threats to public health [2].

In summary, the excess of information and misinformation about COVID-19 on the internet, especially on social networks, can be a threat to health. Websites and social media vary considerably in their quality and the authenticity of their content, whic be very dangrous for heath peop content, which can health. People can be confused by the amount of (mis) information. However, several health organizations are operating around the world (e.g., WHO, UNICEF and ICRC), and often use the internet as a tool to promote online information about COVID-19. Therefore, strategies developed by governments, health institutions and technology and communicatio indispensable in combating the current pandemic.

\section{Authors' contribution}

Edson da Silva and Marileila Marques Toledo contributed to the conception, elaboration, writing and approval of the article. Authors are responsible for all aspects of the work, ensuring the accuracy and completeness of any part of the article.

\section{REFERÊNCIAS}

1. Cuan-Baltazar JY, Muñoz-Perez MJ, Robledo-Vega C. Pérez-Zepeda MF, Soto-Vega E. Misinformation of COVID-19 on the Internet Infodemiology Study 2020 JMIR Public Health Surveill 2020; 6:2, e18444.

2. Merchant RM, Lurie N. Social media and emergency preparedness in response to novel coronavirus. JAMA 2020.

3. Van Bavel JJ, Boggio P, Capraro V, Cichocka A Cikara $\mathrm{M}$, Crockett $\mathrm{M}$, Ellemers N. Using social and behavioural science to support COVID-19 pandemic response 2020.
4. Garrett L. COVID-19: the medium is the message Lancet 2020; 395(10228: 942-943.

5. Zarocostas J. How to fight an infodemic. Lancet 2020; 395(10225):676

6. World Health Organization. Munich Security Conference. Available online: https://www.who.int/dg/ speeches/detail/munich-security-conference (accessed on 10 Abril de 2020).

7. Pulido CM, Ruiz-Eugenio L, Redondo-Sama G, VillarejoCarballido B. A New Application of Social Impact in Social Media for Overcoming Fake News in Health. Int J Environ Res Public Health 2020; 17(7):2430.

8. Hao K. El coronavirus en la era de las redes sociales: De epidemia a 'infodemia'. Disponível onl-ine: https:// www.technologyreview.es/s/11887/el-coronavirus-enla-era-de-las-redes-sociales-de-epidemia-infodemia (acessado em 20/Abr/2020). 